\title{
TRAFFIC LIGHTS ON CONSECUTIVE INTERSECTIONS AND PEDESTRIAN CROSSINGS ALONG LINEAR SETTLEMENTS LOCATED ON NATIONAL ROADS
}

\begin{abstract}
Alina Burlacu, PhD Student, Technical University of Civil Engineering Bucharest, The Faculty of Railways, Roads and Bridges and Team Leader at Traffic Design Department, SC Search Corporation SRL, Romania e-mail: burlacu_alina@yahoo.com

Mihai Dicu, Prof.PhD.eng., Technical University of Civil Engineering Bucharest, The Faculty of Railways, Roads and Bridges, e-mail: mdicu@ @cfdp.utcb.ro

Valentin Anton, Assoc.Prof.PhD.eng., Technical University of Civil Engineering Bucharest, The Faculty of Railways, Roads and Bridges, e-mail: vali@cfdp.utcb.ro
\end{abstract}

\section{Abstract}

In Romania, with time, settlements located along the main roads have developed and transformed into linear towns, with significant local and connection traffic, important administrative, economic, commercial and touristic activities concentrated in the central area, as well as pedestrian traffic of over 200 pedestrians per hour in the main pedestrian crossings on the route.

The object of the present study is made by a series of junctions situated on National Road 1 in Busteni town, on a dangerous road sector. For this study, traffic measurements, simulations and suggestions for improving the existing situation were made.

Based on the simulated traffic flows, there were performed capacity analysis with PTV Vissim and Traficware Synchro softwares, and were developed appropriate planning solutions for the intersections, resulting in tables with extracted performance indicators based on micro simulation of the traffic values. Also planning solutions for horizontal design and proposals for traffic lights were made for junctions that can not operate under priority traffic on one direction or which are presenting traffic safety risk.

Based on the traffic data, it was taken in consideration the necessity to make planning proposals and to develop design solutions immediately applicable, with minimum intervention.

Solutions will refer to the geometric planning of the intersections, but with new plans and timings for traffic lights, including proposals for new equipment; regulating the traffic flow: development/ refurbishment of intersections and pedestrian crossings; optimization of routing programs in order to achieve a higher level of service and more efficient traffic control indicators; segregation of pedestrian movements by vehicles traffic, implementation of physical devices to lock / channel the traffic.

Keywords: traffic study, linear settlements, road traffic, intersections, road safety 


\section{INTRODUCTION}

Linear village or linear locality is that kind of area where humans are developing activities along a main road. This type of area is common in Romania along the national and county roads. It can be also observed in other Central or Western European countries and it is common to small size cities/villages, especially where geography and/or topography of the area does not allow much expansion on the side.

Specific human activities have been developed in time along the main central road: housing, shopping, services, recreational and economic related ones (small industries). Beside this, as the time has passed, the linear village is extended on specific areas not so close to the main road, but getting access to it via the local streets or roads. Thus, it is obvious that this kind of main central road get more functions to be fulfilled: flow function (to ensure a reasonable travelling speed and Level Of Service), distributor function (to ensure the access to lateral developed areas) and access function (to ensure direct access to the activities developed at the roadside directly).

This mixture of functions gives the opportunity to different traffic participants with different purposes to use the main road. Both vehicles and vulnerable traffic participants like pedestrians, bicycles and children make use of this road, either to travel along it when footways are not provided or by crossing it to get access to specific locations as schools, markets, shops, banks, restaurants, etc. Thus, first and the most critical conflicts are given by the interactions between vehicles and vulnerable road users: pedestrians, bicycles and children.

The national road section DN 1 placed on Busteni locality territory is requested for the generated traffic by the local tourist activities, but also serves to others important tourist area in the neighbourhood: Sinaia, Azuga, Predeal.

Figure 1 shows the traffic evolution trend on the national road section DN1 that includes linear village Busteni, as resulted from the traffic study performed by Search Corporation for Bucharest - Brasov motorway in hypothesis without motorway. 
ROMANIAN JOURNAL

\section{OF TRANSPORT INFRASTRUCTURE}

Alina Burlacu, Mihai Dicu, Valentin Anton,

Traffic lights on consecutive intersections and pedestrian crossings along linear settlements located on national roads

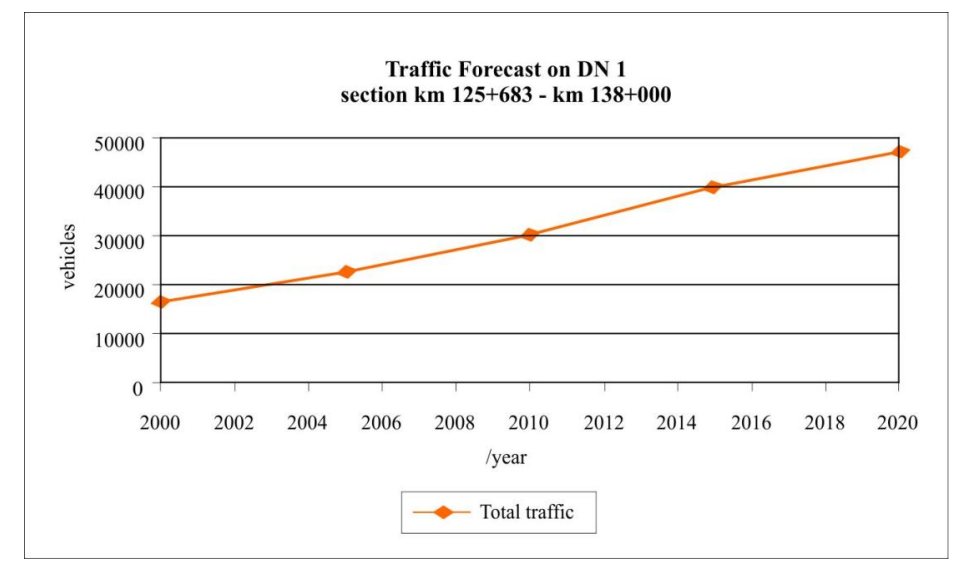

Figure 1. Traffic forecast on DN 1

\section{TRAFFIC DATA}

The project team from Search Corporation has proceeded on a field survey in Busteni during the month of November 2010, to identify the main characteristics of DN 1 and of local streets and access areas linked to the main road, in order to establish the traffic counting locations and to define the working procedures and schedule for the traffic counts.

The traffic data collection was carried out through manual measurements in DN1 sections and on 10 local streets/roads where they cross DN1, and also through automatic counts in five specific sections of DN1.

The automatic traffic counters can identify the type of vehicle (car or truck) and they have been scheduled to register the traffic flows for two weeks, four days per week (Thursday, Friday, Saturday and Sunday), in order to collect information to obtain the traffic pattern (per hour, day, week). One of the DN1 sections where traffic is registered automatically is doubled by the manual counts in order to have a more detailed distribution of traffic flows by type of vehicles.

\subsection{Vehicle traffic}

At the survey sections, it was found that vehicles travel with mean speed between $70 \mathrm{~km} / \mathrm{h}$ at hours with low traffic (in the night and early in the morning) and $30 \mathrm{~km} / \mathrm{h}$ at peak hours (between hours 10:00 - 18:00).

The traffic volume registered during working days is higher then the traffic volume registered during week-ends, even though no significant peaks are noticed. Figure 2 gives the daily variation of the total traffic and variation of 
the heavy vehicles traffic recorded on DN1 at a survey section placed in the linear village Busteni (between Poiana Tapului and Busteni Center).

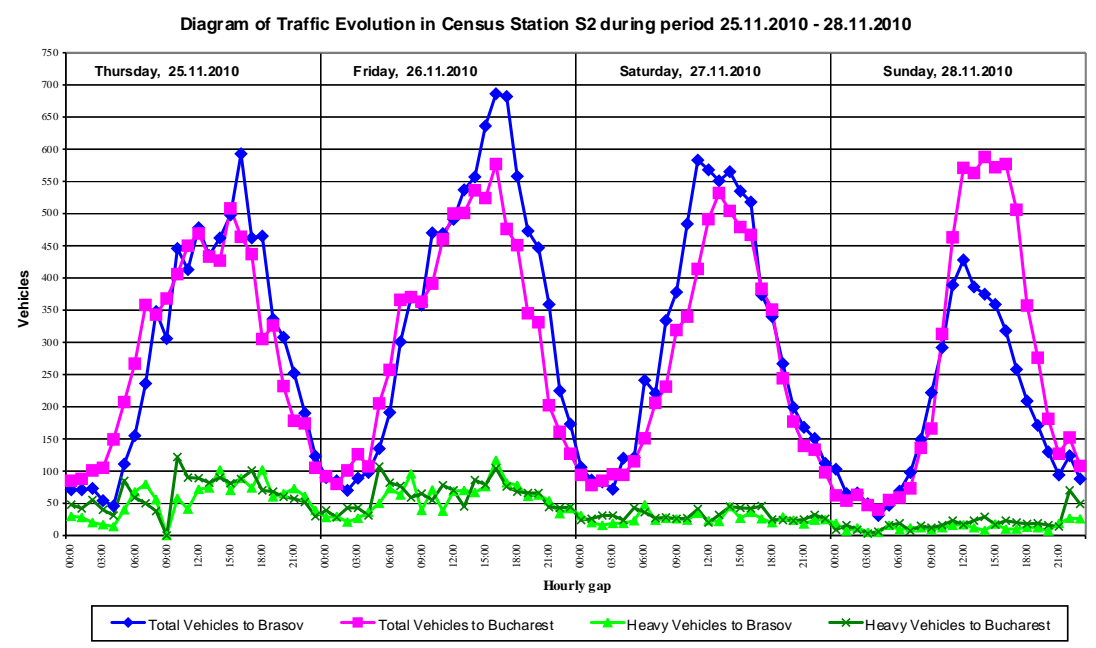

Figure 2. Diagram of daily traffic evolution

The peak hour is Friday in hour gap 16:00 - 17:00. Figure 2 gives hourly intervals with high traffic volume, where the peak hour is included. The maximum hour traffic is $8 \%$ of the total traffic on 24 hours.

Given the Annual Average Daily Traffic (AADT) level, in November (when the traffic survey was made) a lower traffic level is recorded. The maximum traffic volume corresponds to August.

Using the program Synchro, a simulation of the present traffic on the road network of the linear village Busteni was made and it was found that given the size of the vehicle flows from survey sections, in average, the transit is in this interval of time:

- for the direction Sinaia - Predeal, $80 \%$ of total

- for the direction Predeal - Sinaia, $73 \%$ of total

- the rest being local traffic of Busteni locality or connection traffic between this and environment territory.

About traffic capacity we can specify that the vehicle traffic on DN1 at peak hour at level of August exceeds significantly the traffic capacity, relating to the Norm for roads capacity, or to STAS for streets capacity.

Concerning the capacity of the main intersections from DN1, where the traffic from accesses has values over $100 \mathrm{pcu} / \mathrm{h}$, this is exceeded especially due to the high traffic values on DN1. In these intersections, especially for left turn, of entering on DN1 from access, the level of service resulted from calculus is 
"F", as for the whole intersection. Thus for a better understanding of the way these intersections from DN1 operate, a dynamic simulation of the traffic was made with the programs Synchro and PTV Vissim, taking into account the present layout of the intersections, the vehicles and pedestrians traffic. Simulations were made both for a mean traffic at AADT level, and for maximum traffic corresponding to August.

\subsection{Pedestrian Traffic}

The pedestrian traffic has significant values of over 200 pedestrians per hour in November and, 400 - 500 pedestrians/hour respectively, in August, at the peak touristic season, mainly at Busteni Centre area. This generates important problems related to vehicle flows (queues of vehicles on DN1 due to frequent crossing of the pedestrians at zebras). Another area, where pedestrian traffic is high enough to generate conflicting locations with risk of accident, is the area Centre - North.

\subsection{Traffic environment, parking capacity}

Taking into account that the linear locality Busteni is an appreciated touristic spa, one of the problems it faces especially in the summer time is finding a parking lot, associated with the need of information and guidance to important places.

Although in November, the month when traffic data were collected, the parking capacity wasn't totally used, the deficit of parking lots from periods with maximum traffic generates malfunctions of traffic running.

By instance, especially in the central area of the town, in the neighbourhood of some economic units or commercial centres, local widening were made of about $1,5-2 \mathrm{~m}$, that are used as parking lots, this involving additional manoeuvres on traffic lane. Of course, it can be possible in some situations, to be a favourable element for an accident and as result these parking lots should be eliminated and alocated in some other place, with access from lateral streets.

\section{TRAFFIC STUDY}

The collection and processing of the counted data from the analyzed junctions allow us to determine the maximum hourly traffic flows, values which 
are the basis in dimensioning intersections capacity. Graphically, the maximum hourly traffic flows are represented by traffic diagrams.

Based on simulated traffic flows, capacity analyses were made using the program Syncro and solutions were developed in order to obtain an adequate planning of the intersections. This software allows, through micro simulation of traffic values, to obtain a large number of performance indicators of junctions. Based on these indicators, planning and traffic light solutions for each intersection can be compared and placed on levels of service (LOS), so that the optimal solution can be highlighted.

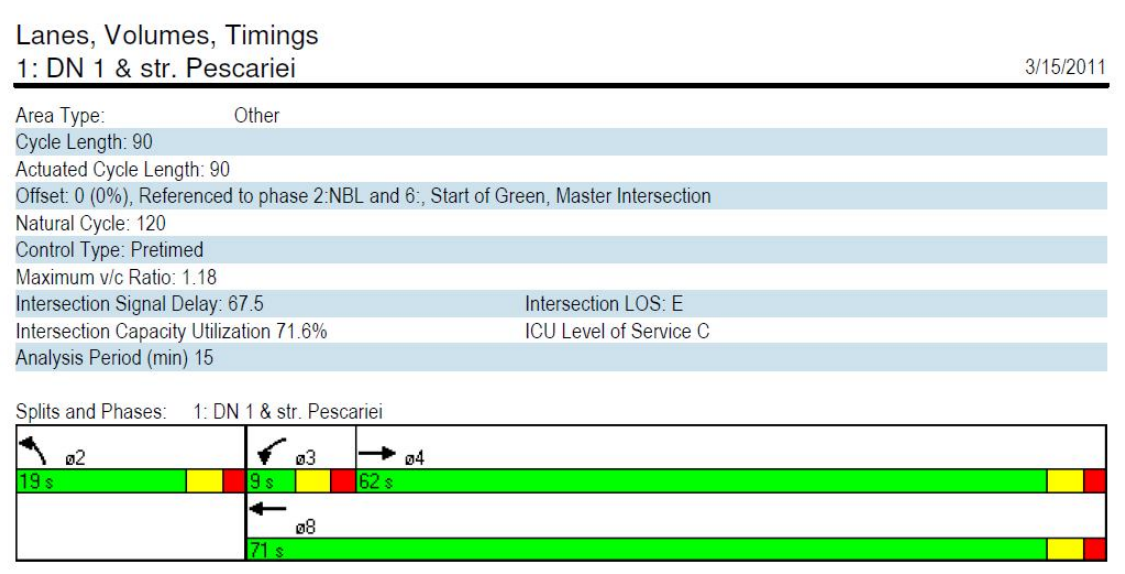

Figure 3. Example of traffic light simulation in Synchro

The analysis module of the program Synchro was used for the capacity analysis in the intersections proposed for traffic lights. In this analysis module we used as input data the following parameters: traffic light cycle length, the share of green light duration for each phase of the cycle, the existent geometry of the junction, traffic flow on each access and travel direction, and the output data for each junction consists in the level of service, the average delays, queue length, emissions of pollutants.

The program Synchro has the following advantages:

- introducing input data in the design module, such as existent geometry of the junction and traffic volumes on each access and travel direction, in order to obtain optimal cycle, the optimal sequence of phases and the optimal duration for green light in each phase (Figure 3);

- for a particular cycle of traffic lights and a particular volume of traffic, in the evaluation module the output data is the cost for each road user. 
As a result of the tests performed with the program Synchro for each analyzed junction, it has been developed an outline with the functioning of the intersection on traffic phases, and also an ongoing plan of phases in characteristic periods for working or non-working days, in different times of day (peak hours and normal hours).

Regarding the optimization of the intersections so that each one operates independently on local area, it was analyzed the current arrangement and improving solutions were elaborated according to the estimated traffic circulation and current traffic regulations, transposing the concepts used for reorganized intersections into detailed solutions.

For the timing of the traffic circulation on the axis, proposals were made in order to modify the actual geometry of the junctions, such as left turn lanes or right turn lanes, as shown in the figure below.

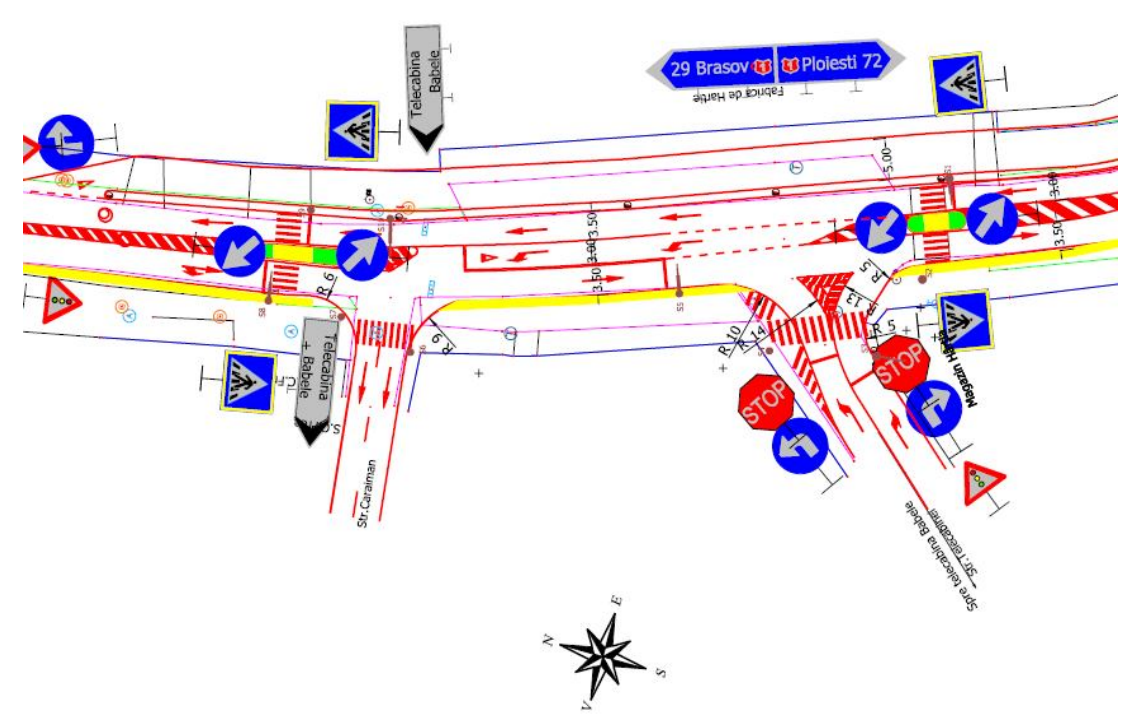

Figure 4. Example of proposed planning solution

Also, uneven solutions for the crossing over of the pedestrians were taken into consideration, such as footbridges or pedestrian subway passages. From traffic analysis they turned out to be ineffective and not feasible for two reasons: first of all, a highway is designed to take over the transit traffic from DN 1, so the traffic flow will considerably decrease; second, the width of the national road in Busteni is between seven and nine meters, so most pedestrians will rather cross over illegal rather then walk three or four times more on a footbridge/ underground pedestrian passage. 


\section{ROMANIAN JOURNAL OF TRANSPORT INFRASTRUCTURE}

At the same time an analysis was made regarding the traffic lights plans and the traffic circulation on the main axes of movement. Based on this analysis there were identified and established the conditions under which the right turn can be removed from under traffic lights.

To improve the traffic circulation on the axes, especially on those with one way or on traffic routes separated by median large green areas and wide interior storage space, the timing of traffic lights in a system of "green line" was investigated.

The calculus of the optimal cycle length and of the duration for "green line" for a main corridor was also made with the program Synchro. After entering the input data set in the Linear Scheme, the program provides data regarding the maximum band width of "green line" for a route, according to the traffic light cycle, the splits on the corridor direction (green light on the corridor compared to the entire cycle) and a certain traffic speed (resulting as optimal) to go through the corridor.

Also, for pedestrian crossings from the routes between the intersections was analyzed their continued appropriateness, and for each case proposals for planning, traffic lights or demolition were made.

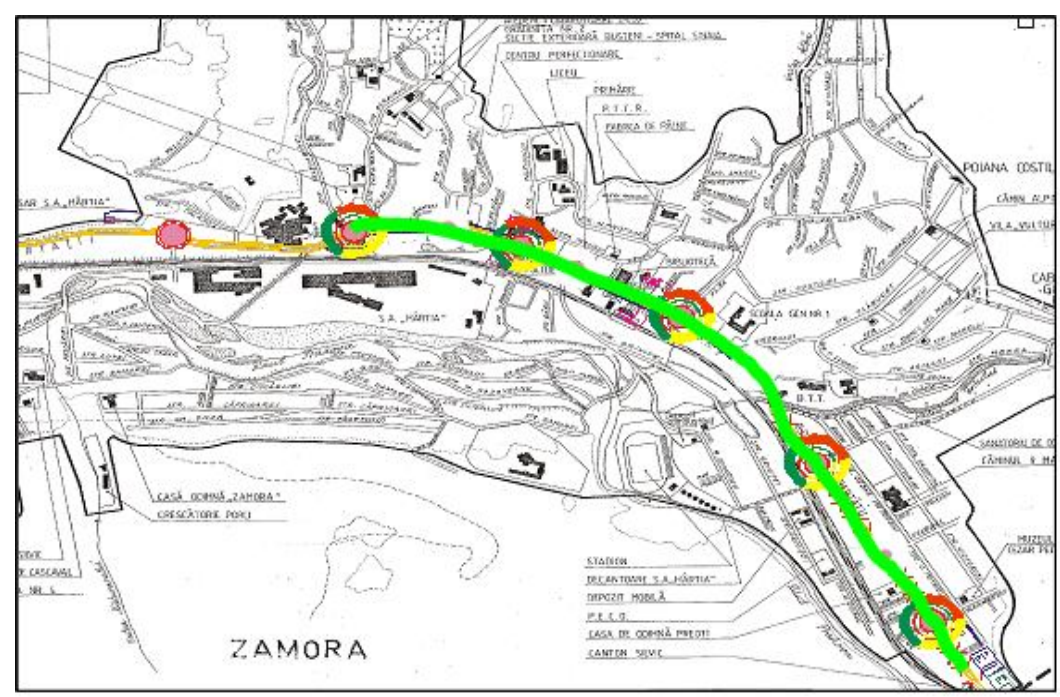

Figure 4. Green line of a continuous flow between the analyzed junctions

\section{CONCLUSIONS}

Analysing the data from the exported tables with performance indicators, it is noticeable that the proposed planning solutions for the junctions not only will contribute to a better channelling of the traffic flow and a better order in the 


\section{ROMANIAN JOURNAL OF TRANSPORT INFRASTRUCTURE}

movement of vehicles and pedestrians, with significant road safety benefits, but also to a significant reduction of the duration of travel.

In this regard, the following were developed: planning solutions in the horizontal plane, immediately applicable, where appropriate; proposals for traffic lights in intersections that don't function properly or present traffic safety risks; optimization of routing programs in order to achieve a higher level of service and more efficient traffic control indicators; segregation of pedestrian movements by vehicles traffic; implementation of physical devices to lock / channelling the traffic.

By introducing traffic lights to the analyzed junctions and their correlating functioning, the traffic safety is improved due to the clear regulation regarding the alternative occupation of the roadway by vehicles and pedestrians. At the same time, the traffic flow is improved throughout the network and the time travel is reduced, along with the waiting time across the junctions and the emissions of pollutants.

\section{REFERENCES}

[1]. "Road Safety Pilot Project on National Road 1 Bucharest Brasov", Search Corporation \& Finnroads, 2004

[2]. “Road Safety Pilot Project in Linear Village Busteni”, Search Corporation \& NEA, 2004

[3]. “Project for Planning of Junctions in Linear Village Busteni”, Search Corporation, 2011

[4]. David Suciu, Anca Damian: "Road Safety Pilot Project in Linear Village Busteni”, Roads and Bridges Magazine, no. 8, no.9, no.10, 2004

[5]. "Highway Capacity Manual", Transportation Research Board of the National Academies, 2010

[6]. "Traffic Signal Software - User Guide, Synchro Studio 7, Synchro plus SimTraffic and $3 D$ Viewer", Trafficware 